\title{
STUDY THE EFFECTS OF REACTIVE MATERIALS REPLACEMENT ON SOME PROPERTIES OF CEMENT MORTAR
}

\author{
Mohammed J. Kadhima,*, Raeid K. Mohammed Jawad and Hamza M. Kamal
}

Materials Eng. dept., University of Mustansiriya, Iraq - Baghdad (moh materials@yahoo.com)

Received: Aug. 2018 / Accepted: Dec., 2018 / Published: Dec., 2018

https://doi.org/10.25271/siuoz.2018.6.4.543

\begin{abstract}
:
This study involves natural--materials replacement and its reaction with cement mortar behavior for many mortar samples under variable curing time with constant water to cement ratio $(\mathrm{W} / \mathrm{C}=0.5)$. In this research some properties such as (compressive strength the surface hardness and water absorption test), were affected by adding small ratios of powder (from (RHA) and (BRP) particles) as replacements to the Ordinary Portland Cement (OPC) / type (I). The percentages of natural materials additives replacement on the mixture of mortar include $(0,5,10,15$ and $20 \%)$ with constant $(\mathrm{W} / \mathrm{C})$ ratio. Also, the amount of the fine aggregate used was three times the amount of cement. The results showed that, the compressive strength and splitting tensile strength and water absorption of the mortars for (replacement) gives better properties than mortar without replacement in all tests. Best enhancements in properties for mortars with pozzalanic replacements were achieved at (15\%) for (RHA) and 10\% for (RBP) replacement from weight of cement.
\end{abstract}

KEYWORDS: Brick reactive powder, Rise Husk Ash, Compressive strength, Flexural strength

\section{INTRODUCTION:}

Supplementary cementitious materials (SCMs) (i.e. pozzolonas) are used to partially replace cement in concrete They are often added to concrete to make the mixtures more economical, reduce permeability, increase strength, or influence other properties. Typical examples include natural pozzolonas (like volcanic ash), fly ash, ground granulated blast furnace slag, rice husk ash, and silica fume (Habeeb \& Mahmud,2010).

Pozzolona is a siliceous or alumino-siliceous material that, in finely divided form and in the presence of moisture, chemically reacts with the calcium hydroxide that is released by the hydration of Portland cement to form compounds possessing cementitious properties. Pozzolona is a siliceous or aluminosiliceous material that, in finely divided form and in the presence of moisture, chemically reacts with the calcium hydroxide that is released by the hydration of Portland cement to form compounds possessing cementitious properties.

Pozzolonas react chemically with calcium hydroxide $\left(\mathrm{Ca}(\mathrm{OH})_{2}\right)$ from the hydration of Portland cement to form the main component is calcium silicate hydrates or C-S-H. The (C$\mathrm{S}-\mathrm{H}) \mathrm{gel}$ is the strong binder that hardens in concrete. The product of general formula $(\mathrm{CaH} 2 \mathrm{SiO} 4-2 \mathrm{H} 2 \mathrm{O})$ formed is a calcium silicate hydrate, also abbreviated as C-S- H in cement chemist notation (Chengzhi et al., 1996). Sustainable development was defined as product development should be programmed with no harm, neither for present nor future generations. These harms are studied and classified into social, environmental impacts, and economic (Alireza et al., 2010).

Cemented materials were the first building material in the world, and the most broadly one was used in every civil engineering works type, and their production was increasing yearly (Hosseini et al., 2009), (Shaikh \& Than, 2014). the increased volume of debris were produced from demolish of buildings, roads, and bridges either because ancientness of these construction projects or war. this waste materials became problem in direction of sustainable development because environmental effect by increasing the depletion of natural resources, a big disposal landfill was needed for debris of concrete, and gas emissions associated with cemented materials prepared when natural aggregates were used and from cement manufacture. (Mukharjee \& Barai, 2014), (Obla \& Lobo,2007), (Yadhu \& Devi, 2015). The carbon dioxide $\left(\mathrm{CO}_{2}\right)$ quantity emitted, when cement production approximately (2.46 billion tons/year), was about $(5 \%)$ of all $\left(\mathrm{CO}_{2}\right)$ emissions in the worldwide, and approximately (160 million tons/year) from natural aggregate production (Hasanbeigi \& Lin, 2012), (Jina \& Chen, 2015)

The recycled of cement mortar and concrete as aggregate were most important towards more sustainable construction, and because the cement, natural aggregates, and water use rate is very accelerating, the cement production and demand are rising; yearly world cement manufacture is expected to raise from about (2,540 million tons) in 2006 to about (3,680 million tons), and (4,380 million tons) in 2050 at low and high estimate (Hasanbeigi \& Lin, 2012).

Therefore, in this study the cement mortar was recycled to fine aggregate to replacement natural aggregate (sand) to production new cement mortar and concrete.

\section{EXPERIMENTAL WORK:}

\subsection{Materials:}

There are many materials which are used to prepare specimens, these materials consist cement, fine aggregate, water and recycle cement materials

2.1.1 Water: The water is used for all physical tests and mortars specimens' preparation from mixing and curing stages and it was used for all the mechanical tests that had been carried out.

2.1.2 Fine aggregate: Fine aggregates generally consist of natural sand or crushed stone with most particles smaller than $(5 \mathrm{~mm})$. The most desirable fine-aggregate grading depends on

* Corresponding author

This is an open access under a CC BY-NC-SA 4.0 license (https://creativecommons.org/licenses/by-nc-sa/4.0/) 
the required of work. The sand grading analysis was conforms to the Iraqi Specification requirement of No.45/1984.ALEkadir in Karbala region sand was used as fine aggregate. It was tested to determine the grading and other physical properties. The sand used in this study is according to the standard specifications.

2.1.3 Cement: The type of cement was used in all mixes in this research is the Ordinary Portland cement (type I). Ordinary Portland cement manufactured in Iraq by Tasloga Cement Factory. The chemical analysis of the cement composition used is listed in table (1). The cement concordance with the Iraqi specification (No.5/1984).

Table 1. The chemical composition of ordinary Portland cement (OPC).

\begin{tabular}{|c|c|c|}
\hline $\begin{array}{c}\text { Oxides } \\
\text { Composition }\end{array}$ & $\begin{array}{c}\text { Oxide } \\
\text { content\% }\end{array}$ & $\begin{array}{c}\text { Limits of Iraqi } \\
\text { Specification } \\
\text { No.5/1984 }\end{array}$ \\
\hline $\mathbf{S i O}_{2}$ & 20.26 & - \\
\hline $\mathbf{A l}_{2} \mathbf{O}_{3}$ & 5.50 & - \\
\hline $\mathbf{F e}_{2} \mathbf{O}_{3}$ & 2.19 & - \\
\hline $\mathbf{C a O}$ & 61.39 & - \\
\hline $\mathbf{M g O}$ & 2.29 & $<5.00$ \\
\hline $\mathbf{S O}_{3}$ & 2.5 & $<2.8$ \\
\hline Free CaO & 1.12 & - \\
\hline Loss on Ignition & 3.4 & $<4.00$ \\
\hline Insoluble Residue & 0.71 & $<1.50$ \\
\hline $\begin{array}{c}\text { Lime Saturation } \\
\text { Factor }\end{array}$ & 0.92 & $0.66-1.02$ \\
\hline
\end{tabular}

\subsection{Mortar mixing and Specimens Preparation:}

The suitable mortar mixing was prepared by using cement-sand ratio of $(1: 2.75)$ with $(\mathrm{W} / \mathrm{C})$ ratio of $(0.5 \%)$. The blended cement mortar was prepared using ordinary Portland cement that was partially replacements in $(5,10,15$ and $20 \%)$ by both RHA (Rusk Husk Ash) and BRP (Brick Reactive Powder) particles by weight of cement.

The first stages of mixing procedure consists of spreading the measured cement over the sand then mixing them in dry state, turning over them, backward and forward over all times by shovel till the mixture looks uniform in color. Then make a small depression on top of the heap. The mortar pastes were molded into $(50 \mathrm{~mm})$ cubes for water absorption according to ASTM C642-2004, (20 mm) cubes for hardness. The samples were kept in molds at $(100 \%)$ relative humidity for (24 hours) and then cured in water for $(7,14,28,60,91$, and 120 days)

2.2.1 Compression Strength test: The compression strength tests were done on $50 \mathrm{~mm}$ cube specimens using $(2000 \mathrm{KN})$ compressive machine (ELE machine device). The rate of loading on the cubes was $1.0 \mathrm{~mm} / \mathrm{min}$. Three samples were tested for each, and the average strength was recorded.

2.2.2 Flexural strength test: The flexural test machine was achieved by Tinius Olsen universal material machine device with $(100 \mathrm{KN})$ load is applied in strength of materials laboratory in materials engineering department in materials engineering department/Al-Mustansiriyah University. The recorded final of the all results obtained was represented the average of flexural strength from many prisms. The dimensionof prism was done according to (ASTM 348-02) average strength was recorded.

2.2.3 Water absorption test: The absorption test was carried out according to ASTM C642-2010 [12]A $20 \mathrm{~mm}$ cubic specimen used throughout this test. Equation (1) used for calculating absorption.

Absorption $\%=((\mathrm{Ba}-\mathrm{Aa}) / \mathrm{Aa}) * 100 \ldots \ldots .(1)$

Where:

$\mathrm{Aa}=$ oven dry weight $(\mathrm{gm})$

$\mathrm{Ba}=$ saturated surface dry weight (gm).

\section{RESULT AND DISCUSSION:}

\subsection{Compressive results}

The results of compressive strength of specimen's tests without and with natural pozzolanic materials replacement to mortars are illustrated in figures together in order to show the effect of reactive powder materials replacement on the compressive strength behavior. Figures (1) and (2) shows the variation of days $(7,14,28,60,90$, and 120 days) with compressive strength of blended mortar for (5\%) from (RHA) and (BRP) particles replacement. The amount of (BRP) replacement up to $10 \%$ the compressive strength of cement mortar with (BRP) is increased. With $(10 \%)$ from (RHA) particles replacement the compressive strength increases with curing time increase with the same $(\mathrm{W} / \mathrm{C})$ ratio and the compressive strength properties has improved than the control cement mortar at different curing time, this behavior was shown in figure(3). Slow increase of compressive strength with increasing (RHA) loading with the increasing quantity of (RHA) up to (15\%). The mechanism of (RHA)-particles effect was shown in fig. (6) When increases the strength of mortar with (RHA) particles. Then decrease in strength with $20 \%$ RHA and (BRP) have shown in figures (7) and (8).

The pozzolanic reaction is also accompanied by a reduction in the total volume and size of capillary pores an effect that is equally important for the enhancement of strength. Additional to reduces the amount and size of $\left(\mathrm{Ca}(\mathrm{OH})_{2}\right)$ crystals and fills the voids of (C-S-H gel) structure. The structures of hydrated becomes denser and compact. The pozzolanic reaction by consumption of $\left(\mathrm{Ca}(\mathrm{OH})_{2}\right)$ which led to the formation of an additional $(\mathrm{C}-\mathrm{S}-\mathrm{H})$ that fills the pores system and causing densification effect which improve the microstructure of mortar. 


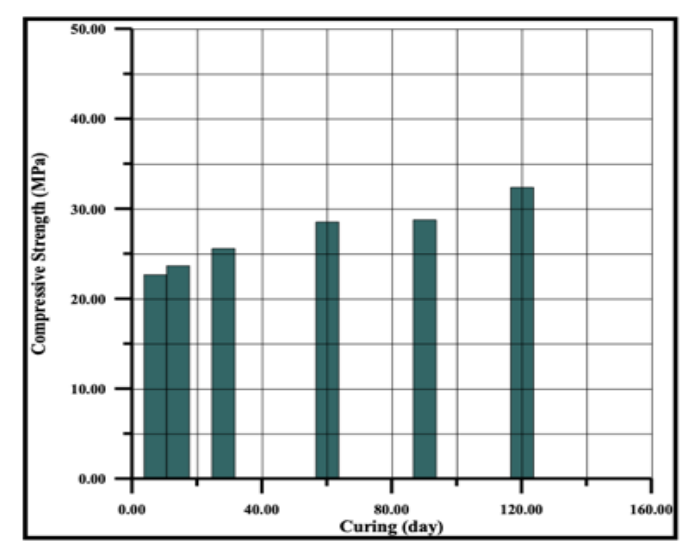

Fig.1 The compressive strength of 5\% BRP

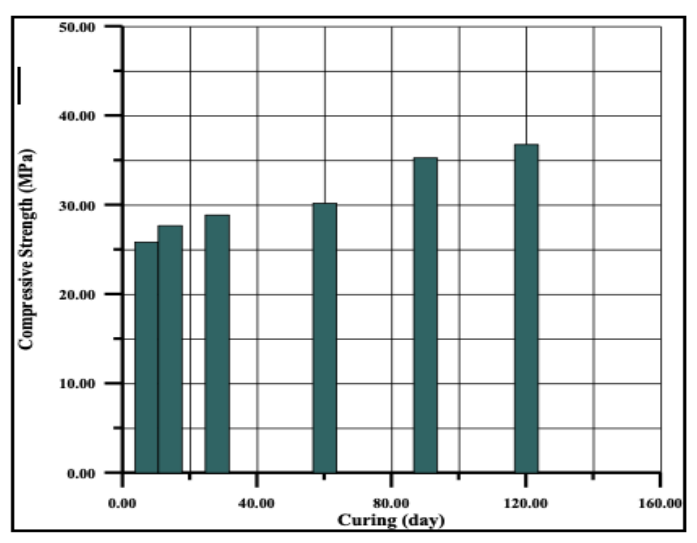

Fig.3. The compressive strength of $10 \%$ BRP

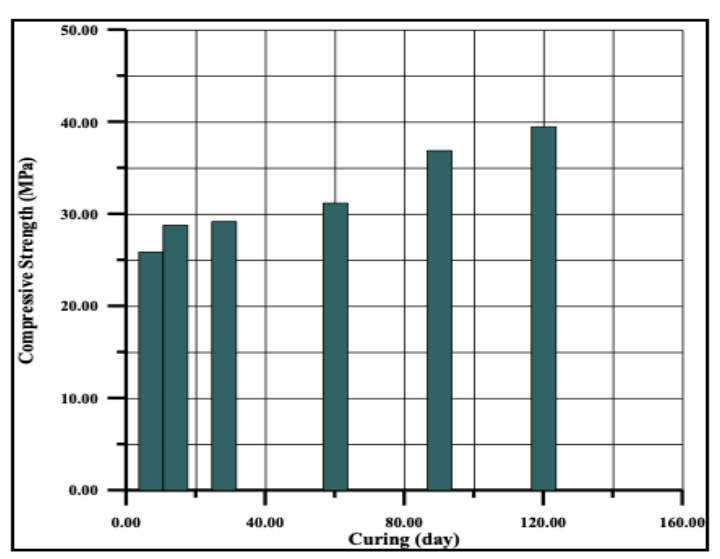

Fig.5. The compressive strength of $15 \%$ BRP

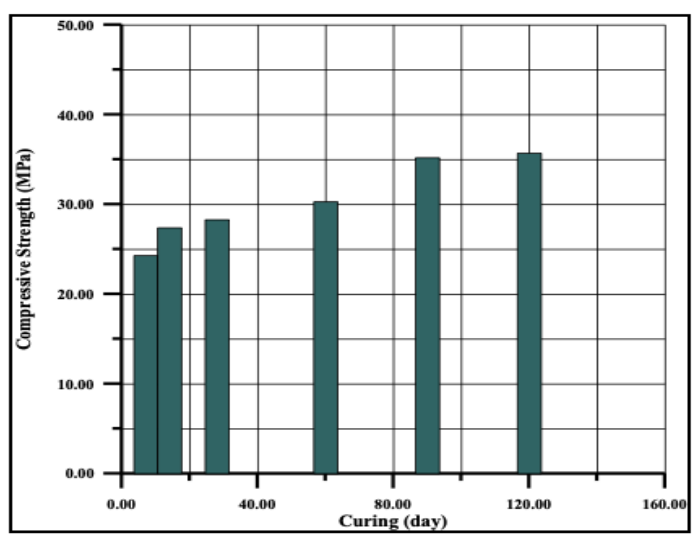

Fig.7. The compressive strength of $20 \%$ BRP

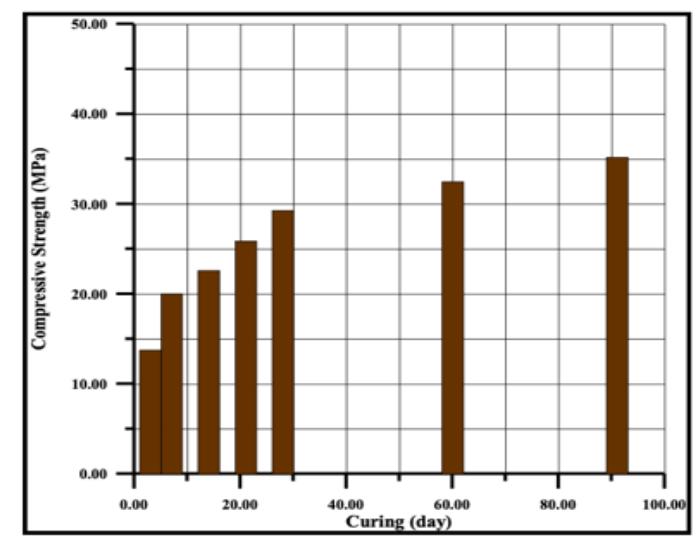

Fig. 2. The compressive strength of $5 \%$ RHA

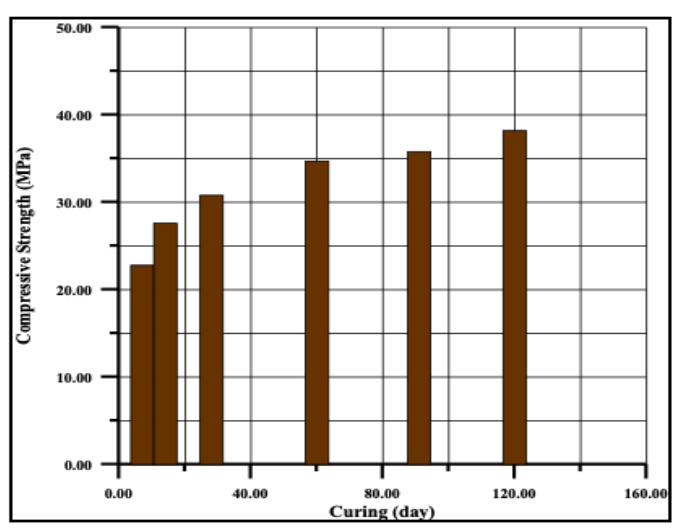

Fig.4. The compressive strength of $10 \%$ RHA

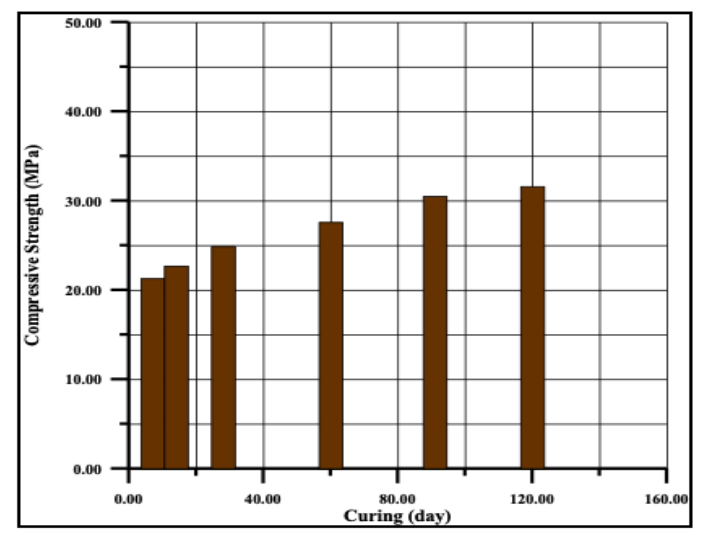

Fig.6. The compressive strength of $15 \%$ RHA

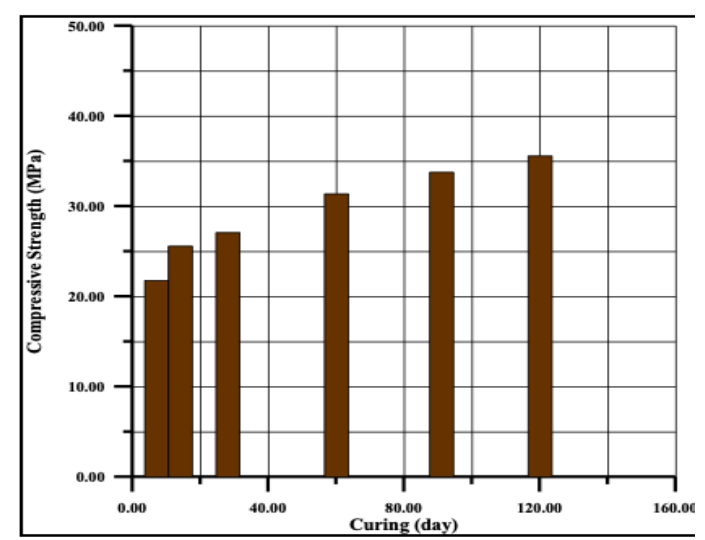

Fig.8. The compressive strength of $20 \%$ RHA 


\subsection{Flexural strength results:}

Mortar prisms tested in accordance with EN 196-1which found the flexural strength and then in compression between control and reactive powder materials replacement.

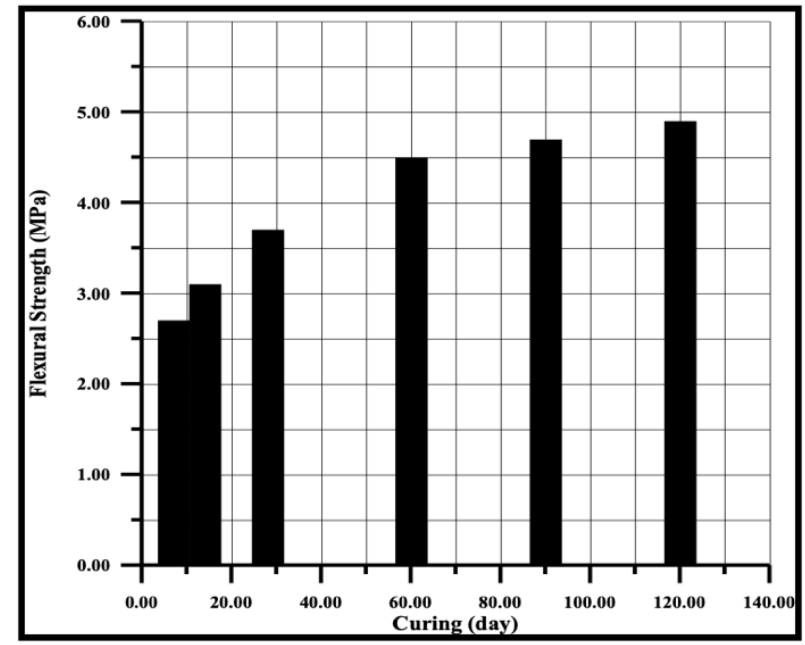

Fig. 9. Flexural strength for control samples

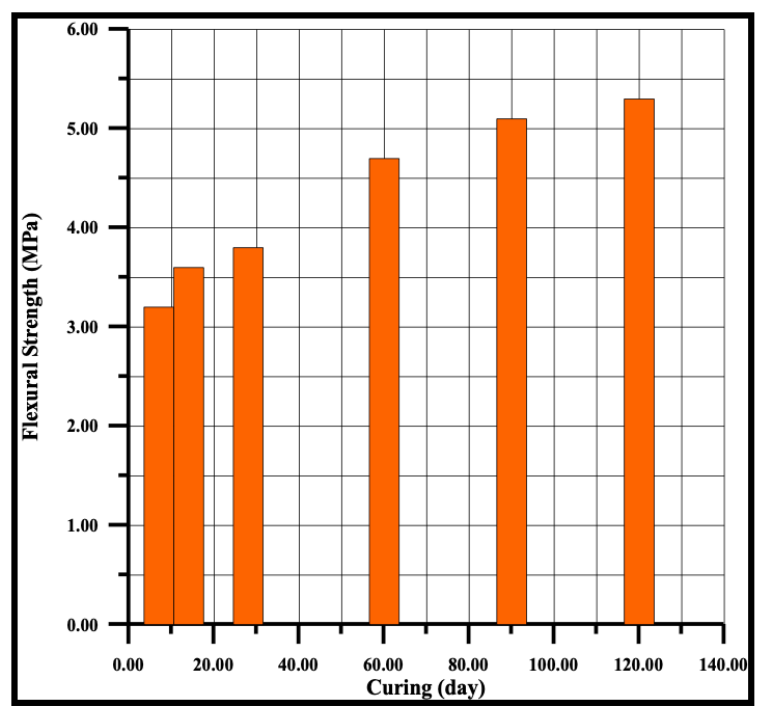

Fig.10. Flexural strength for 5\% BRP

All the mortars made without any replacement (control) samples showed flexural strength results below. The reference cement mortar made without any replacement is shown in figure (9). Flexural strength of control mortar with (5\%) from (RHA) and (BRP) particles mortar, at the first time of curing the $(5 \%)$ from (RHA) and (BRP) particles mortar slightly higher than that for control mortar $(5 \%)$ the flexural behavior can be illustrate in figure (10) and (11) respectively. The effect of nano particles increment 10\% from (RHA) and (BRP) particles can be shown in figure (12) and (13) respectively. With $15 \%$ (RHA) and (BRP) particles the flexural strength improved these behaviors can illustrate in figure (14) and (17) for (RHA) and (BRP) replacement begins to decrease.

Also more generation of strengthening gel could improve the defects of dispersion method of (RHA) and (BRP) particles. In addition, pozzolanic particles recovered the particle packing

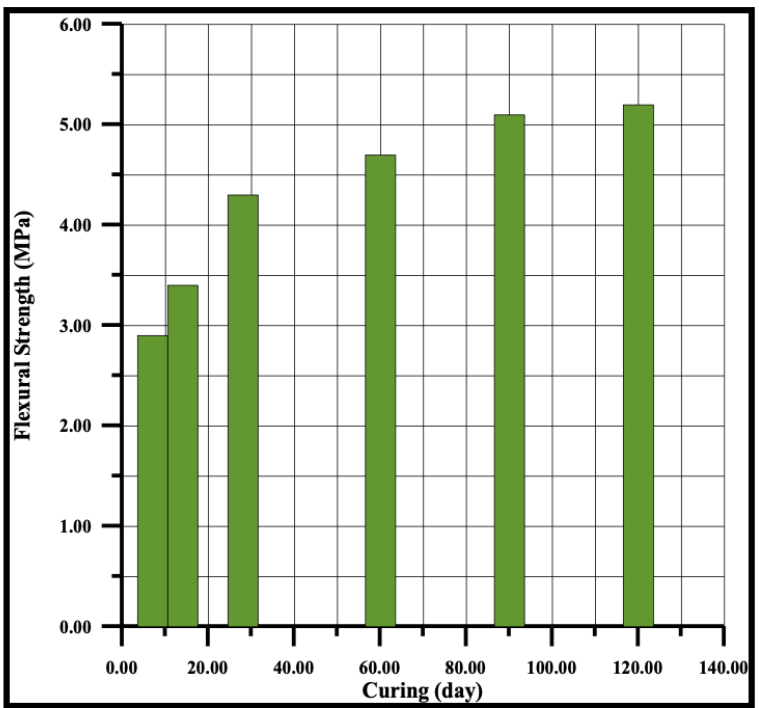

Fig.11. Flexural strength for 5\% RHA

density of the blended cement, directing to a reduced volume of larger pores in the cement paste. These results usually, the pozzolanic powder helps to improve the mechanical performance of cement mortars due to the filler effect of replacement. Therefore, the results reported in this paper suggest that the mixing conditions play an important role with regard to the flexural strength.

Then the behaviors of flexural strength decreases when the (RHA) and (BRP) replacement increases up to $10 \%$ (BRP) and $15 \%$ (RHA). Calcium hydroxide $\mathrm{Ca}(\mathrm{OH})$ and calciumsilicate hydrates $\mathrm{C}-\mathrm{S}-\mathrm{H}$ are the major hydration and reaction products for RHA paste. For these cases observed in figure (14) and (17). The results show that the addition of (BRP) and 15\% (RHA) particles, increasing amount of flexural strength is more than control samples. But the flexural strength decrease when the amount of (RHA) and (BRP) reach to $20 \%$. 


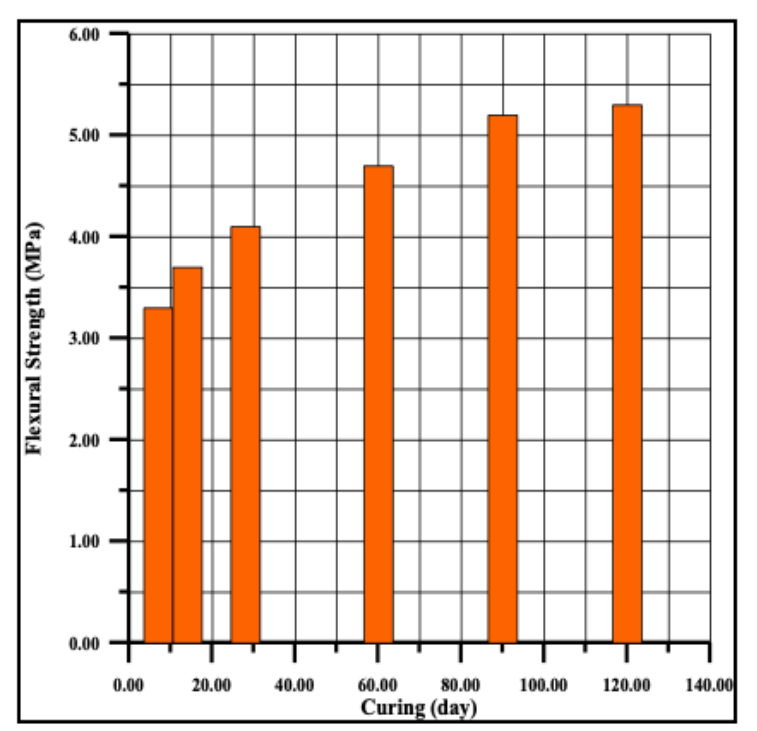

Fig.12. Flexural strength for $10 \%$ BRP

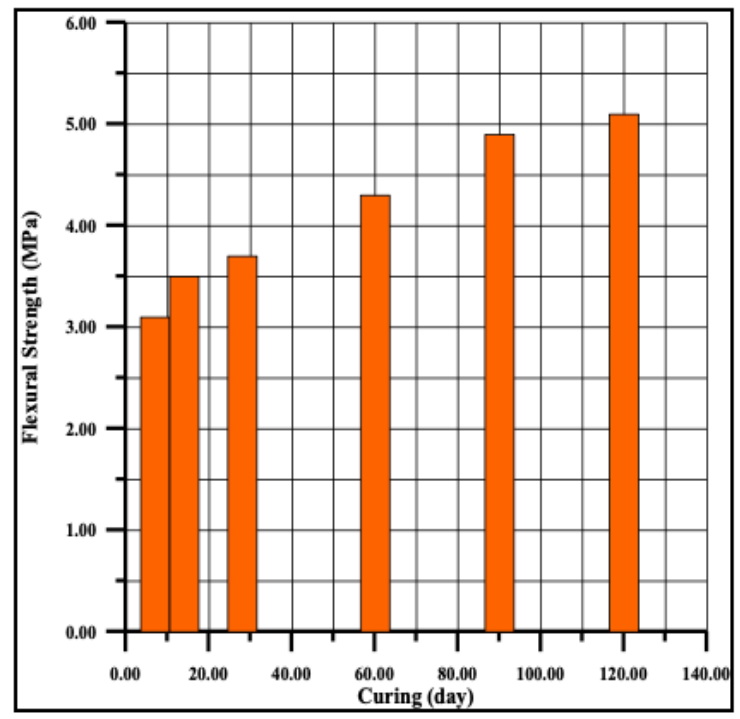

Fig.14. Flexural strength for $15 \%$ BRP

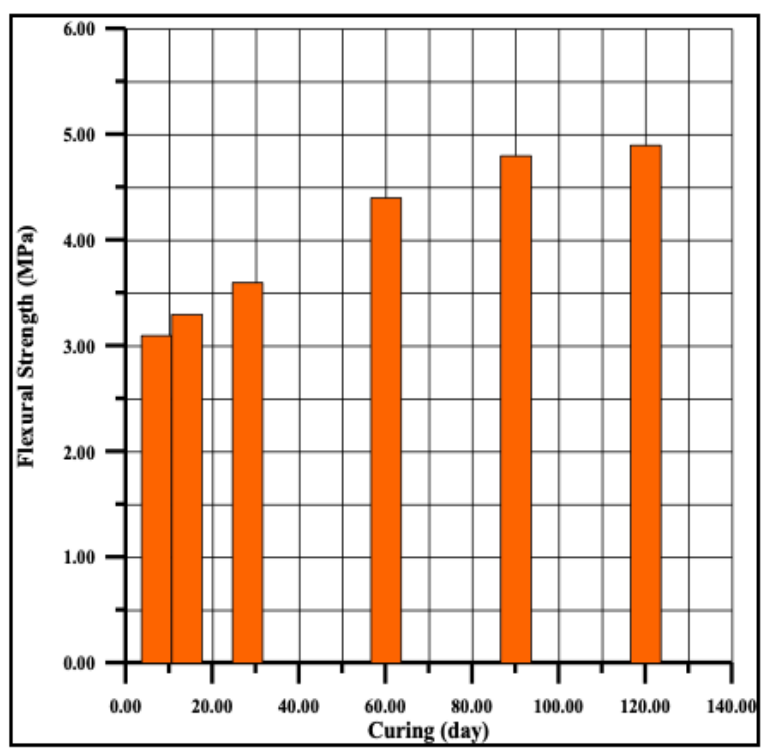

Fig.16. Flexural strength for $20 \%$ BRP

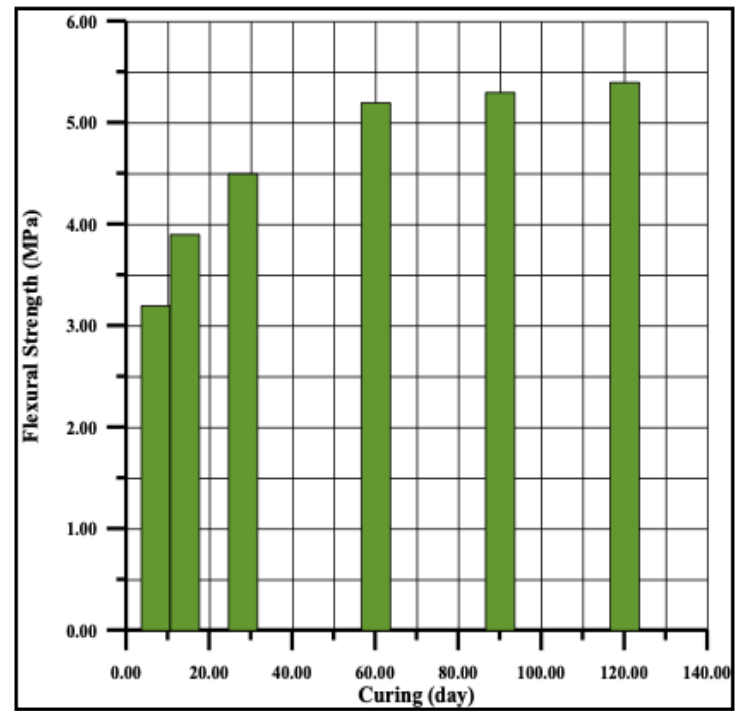

Fig.13. Flexural strength for $10 \%$ RHA

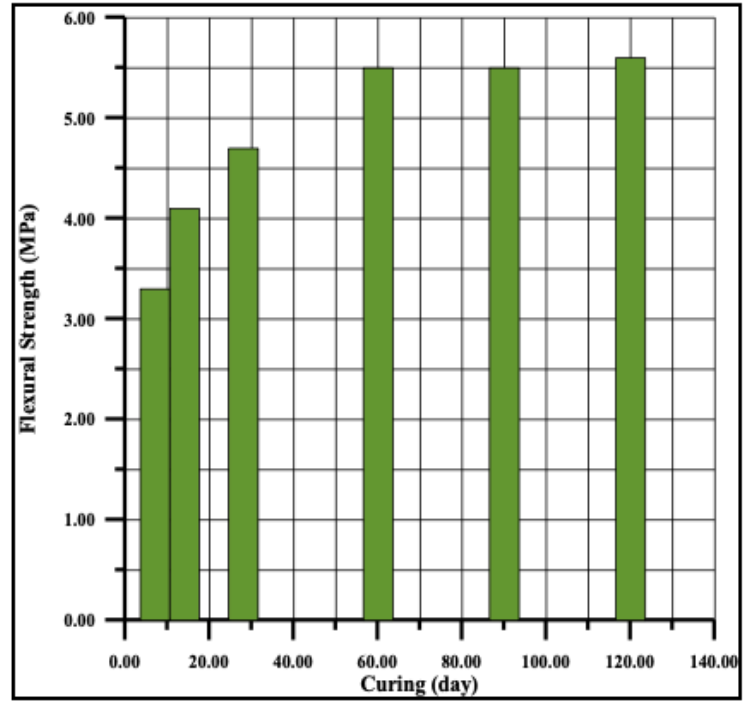

Fig.15. Flexural strength for 15\% RHA

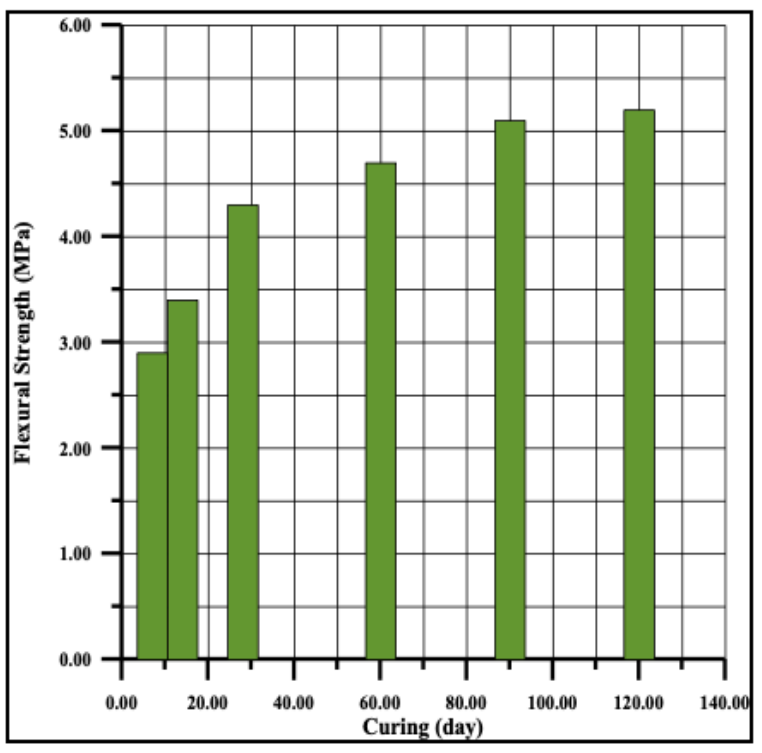

Fig.17. Flexural strength for $20 \%$ RHA 


\subsection{Water absorption:}

One of a most important test to measuring mortar or concrete durability is called water absorption. The total amount of required water absorption that will give an indicator for mortar or concrete durability which water fill and enter into the voids of mortar and saturates the matrix pores.

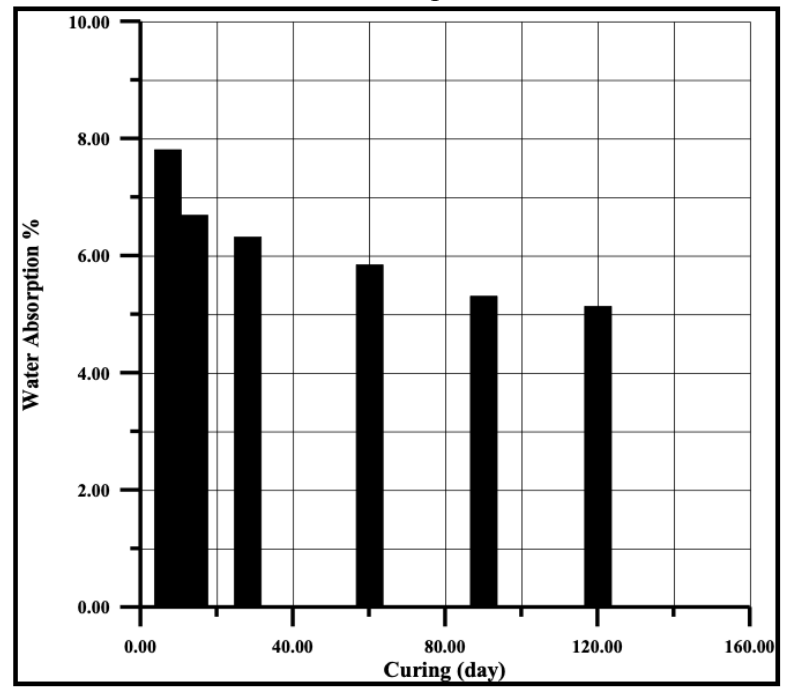

Fig.18. Water absorption for control samples

Figure (18) can illustrate a comparison for the results of water absorption test between the control mortar and specimen contain (RHA) and (BRP) particles replacements. It was found that water absorption decreases in specimens contain $5 \%$

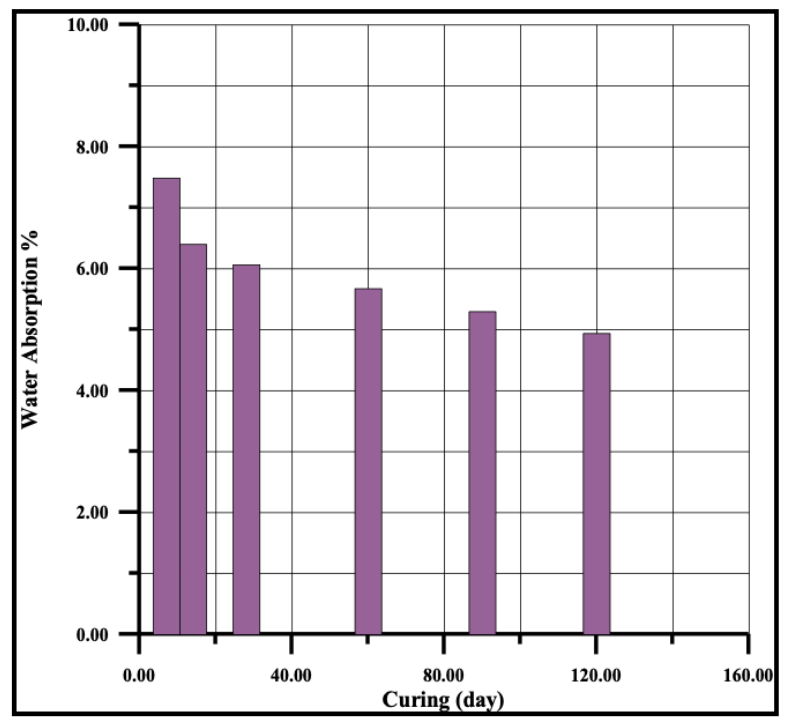

Fig. 9. Water absorption for (5\% BRP)
(RHA) and (BRP) replacement compared with control samples. The results give the indication that, when the amount of (RHA) and (BRP) particles increases it will cause a decrease in water absorption. This behavior can be seen in figures (19) and (20). When the amount of (RHA) and (BRP) replacement reaches $(10 \%)$ as seen in figures (21) and (22) the water absorption will be decreased more than control specimens. As seen in figures (11). When the amount of (RHA) and (BRP) increases to (15\%) and $(10 \%)$ replacement, water absorption reaches its maximum value, this is illustrated in figures (23) and (22).

The materials at (15\%) (RHA) replacement gives the optimum behavior of water absorption This can be attributed to the pozzolanic reaction of the (RHA) that continues with age and consumes the calcium hydroxide to produce additional calcium silicate hydrate. This improvement in the percentage of water absorption is due to the combined action of RHA as a pozzolanic material which reacts with $\mathrm{Ca}(\mathrm{OH})_{2}$ liberated during the hydration of cement to form calcium silicate and calcium aluminates hydrates, which leads to the reduction of the porosity of cement mortar.

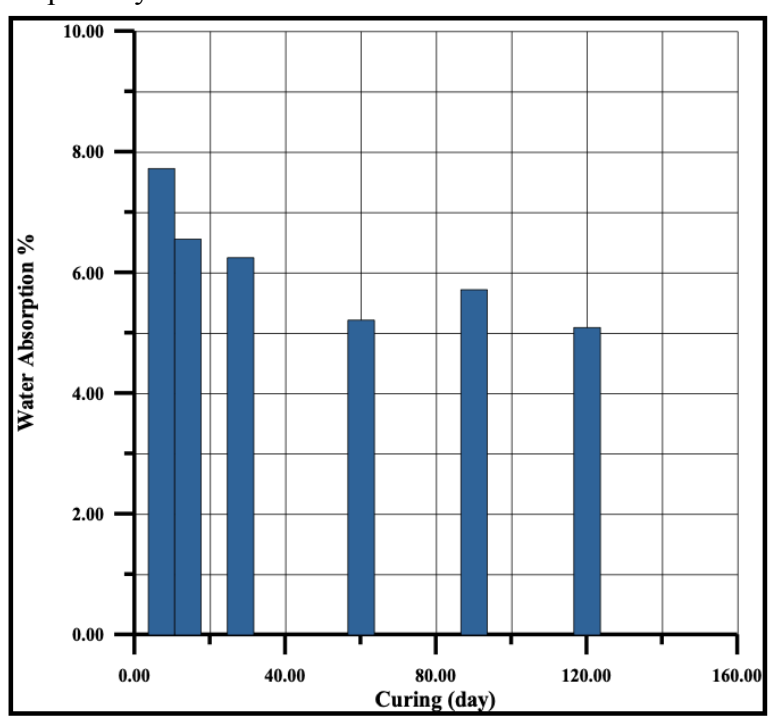

Fig.20. Water absorption for (5\% RHA)

It also functions as filler and as results pozzolanic material occupy space that would otherwise be occupied by water. This action leads to a reduction in the total porosity of the mortar mixes. Then the amount of (RHA) reach to $20 \%$ the water absorption begins to increase compared with controlled samples. Figures (26) represent of (RHA) and figure (23) represented to $15 \%$ (BRP) replacement addition at (20\%). These illustrate the water absorption which begins to increase and near to control specimens. Defects may be generated during the dispersion of (RHA)-particles that causes weak area. 


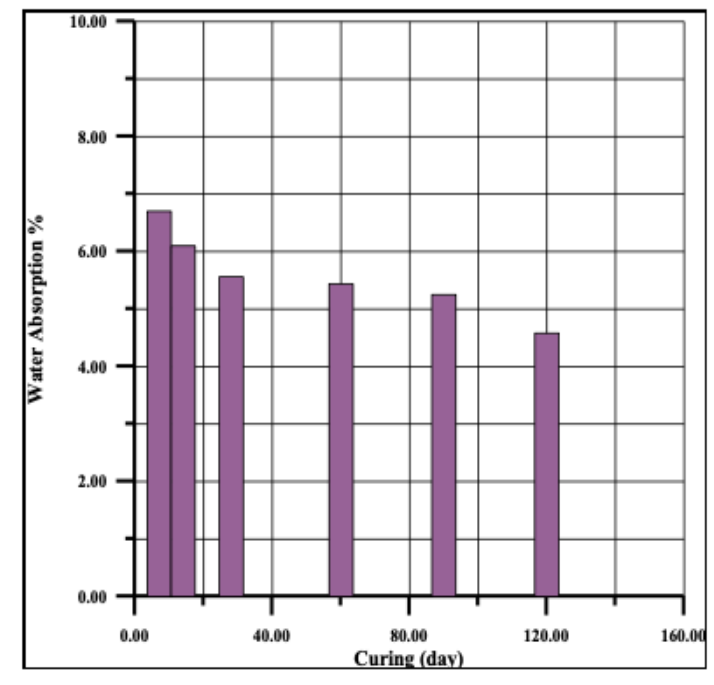

Fig.21. Water absorption for (10\% BRP)

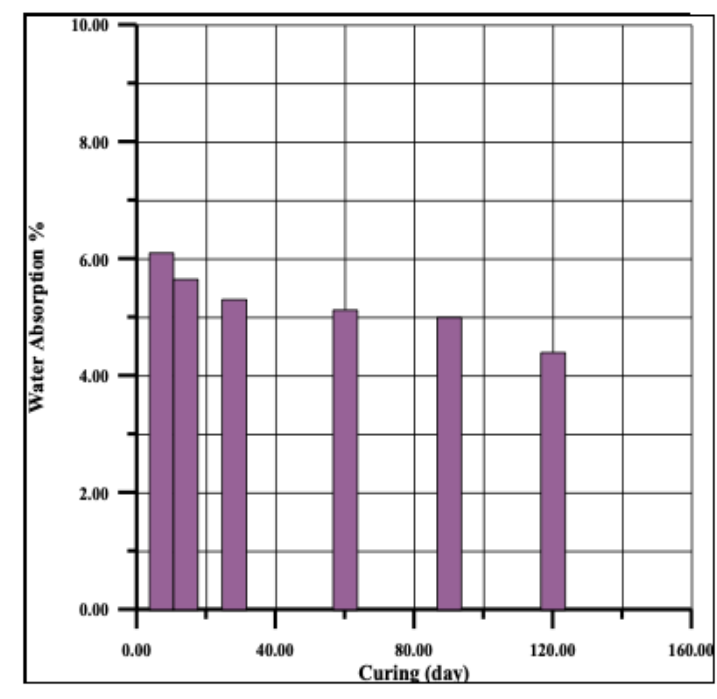

Fig.23. Water absorption for (15\% BRP)

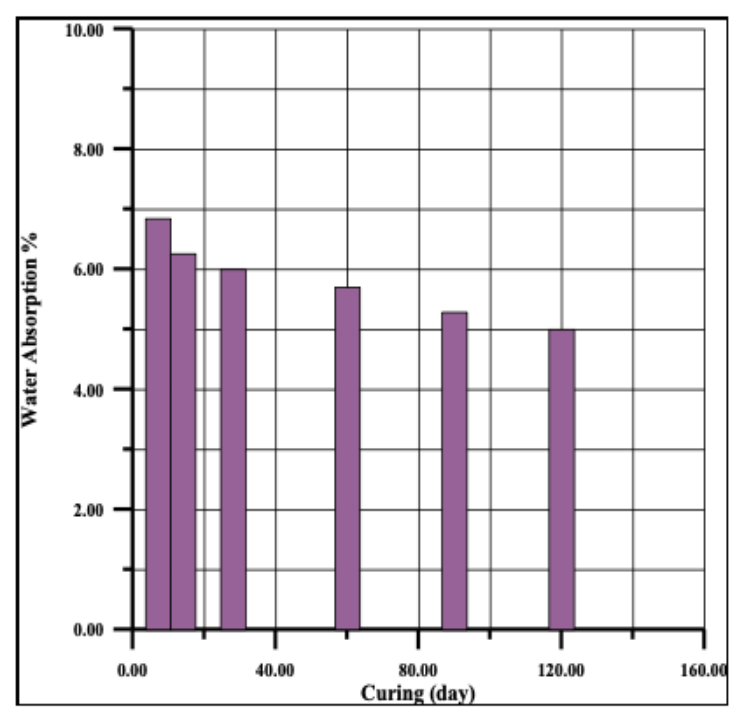

Fig.25. Water absorption for (20\% BRP)

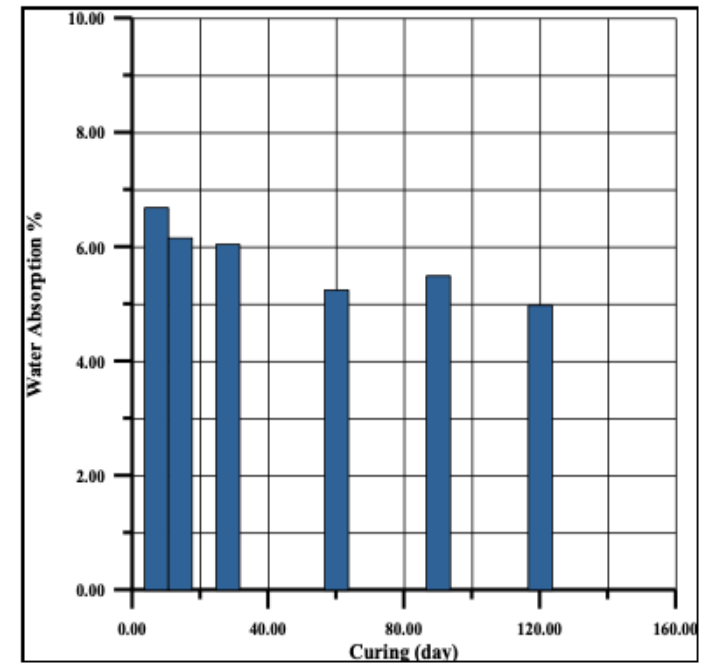

Fig. 22. Water absorption for (10\% RHA)

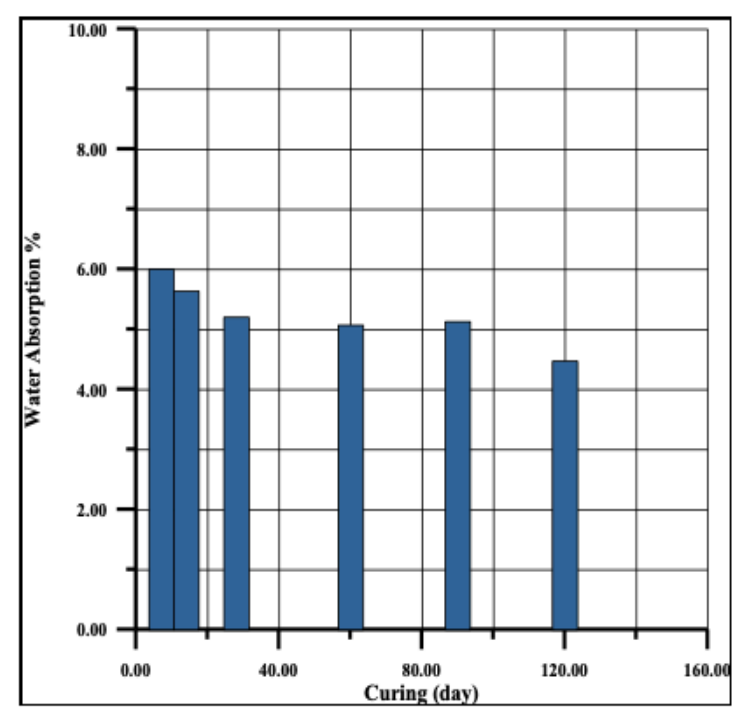

Fig.24. Water absorption for (15\% RHA)

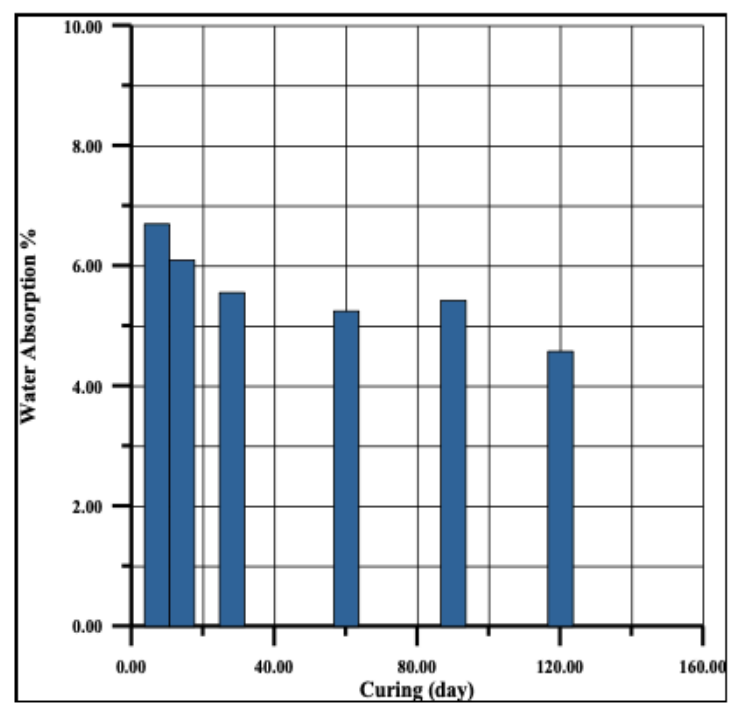

Fig.26. Water absorption for (20\% RHA) 


\section{CONCLUSIONS:}

According to the results from the experimental tests, the following points can be concluded:

1. Application of (RHA) particles (in amount of replacement up to $5,10,15$ and $20 \%$ ) can lead to microstructure development due to their multi functional behavior in the matrix of cement-based materials. This characteristic can enhance both water absorption and surface hardness property of cement mortar specimens.

2. The (RHA)-particles into the matrix of cement mortar that are prevention of growth of harmful crystals such as $\mathrm{Ca}(\mathrm{OH})_{2}$ and, more production of C-S-H gel, micro and nano filling effect, and helping the hydration reaction to be developed due to nucleus-like action.

3. The compressive strength of mortar consist of (RHA) and (BRP) are higher than control mortar at all curing ages.

4. Optimum (RHA) and (BRP) replacement ratio improved the surface compressive at (120 days) compared with control mortar.

5. The water absorption was improved compared to control samples, the enhancement of water absorption by (RHA) better replacement at (120 days) above both controls and BRP replacement cement mortar.

6. The enhancement of strength by (BRP) replacement was achieved especially at (10\%) addition replacement at all curing time.

7. Flexural strength of (RHA) replacement at $15 \%$ better than $10 \%$ (BRP) and control samples at all curing times.

\section{REFRENCES}

A. Hasanbeigi, L. Price, and E. Lin, Emerging Energy-efficiency and $\mathrm{CO}_{2}$ Emission-reduction Technologies for Cement and Concrete Production, Ernest Orlando Lawrence Berkeley national laboratory, No. LBNL-5434E, 2012.
Alireza, N.G., Suraya, A., Farah, N.A.A. and Mohamad Amran, M. (2010) "Contribution of Rice Husk Ash to the Properties of Mortar and Concrete: A Review" Journal of American Science, 6(3) pp. 157-165P.

B. B. Mukharjee, and S. V. Barai, Compressive Strength of Nano-Silica Incorporated Recycled Aggregate Concrete, IJARCSEIED, Vol.: 2 ,Issue: 1, pp. 22-28,08-May,2014

Chengzhi, Z., Aiqin, W., Mingshu, T. and Xiaoyu, Liu,(1996) "The Filling Role of Pozzolanic Material", Cement and Concrete Research, Vol.26, No.6, pp.943-947.

F. Shaikh, H. Odoh, and A. Tahn, Effect of nano silica on properties of concrete containing recycled coarse aggregates. Proceedings of the ICE - Construction Materials. 168 (2) pp. $68-76,2014$

G. Yadhu, and S. A. Devi, An Innovative Study on Reuse of Demolished Concrete Waste, JCEE, ISSN: 2165 784X,Vol. 5 • Issue 5 • 1000185, 2015

Ghassan Abood Habeeb and Hilmi Bin Mahmud (2010), "Study on properties of rice husk ash and its use as cement replacement material", Department of Civil Engineering, University of Malaya, Kuala Lumpur, Malaysia, Material Research. vol.13 no.2 São Carlos.

Hosseini, A. Booshehrian, M. Delkash, S. Ghavami, and M.K. Zanjani, Use of Nano-SiO2 to Improve Microstructure and Compressive Strength of RecycledAggregate Concretes, Nanotechanlogy in Construction , Springer, Berlin, Heidelberg, ISBN978-3-642-00979-2, pp. 215-221, 2009.

K. Obla, H. Kim, and C. Lobo, Crushed Returned Concrete as Aggregates for New Concrete, RMC Research \& Education Foundation Project, pp. 05-13, 2007.

R. Jina, and Q. Chen, Investigation of concrete recycling in the U.S. construction industry, Elsevier Ltd., Procedia Engineering 118,pp. 894 - 901, 2015. 